\title{
Effect of chloramine concentration on biofilm maintenance on pipe surfaces exposed to nutrient-limited drinking water
}

\author{
Se-Keun Park ${ }^{1 *}$ and Yeong-Kwan Kim ${ }^{2}$ \\ ${ }^{1}$ Division of Environmental Science \& Engineering, National University of Singapore, 9 Engineering Drive 1, \\ Singapore 117576, Singapore \\ ${ }^{2}$ Department of Environmental Engineering, Kangwon National University, 192-1 Hyoja-dong, Chuncheon, \\ Gangwon-do 200-701, Republic of Korea
}

\begin{abstract}
This study addresses the effect of specific monochloramine concentration on biofilm density and bacterial functional potential in nutrient-limited water. The efficacy of monochloramine residual maintenance on biofilm density was studied at a range of 0.5 to $2.0 \mathrm{mg} / \ell$, using a $3: 1(\mathrm{w} / \mathrm{w})$ dosing ratio of chlorine to ammonia, with the provision of low-nutrient water $(0.18 \mathrm{mg} / \ell$ as total organic carbon, $0.055 \mathrm{mg} / \ell$ as biodegradable dissolved organic carbon, and $10.5 \mu \mathrm{g} / \ell$ as assimilable organic carbon) using a granular activated carbon (GAC) filter. Biofilm density was monitored using biofilm bacteria counts and analysis of the physiological substrate utilisation profiles in Biolog gram-negative (GN) micro-plates.

The monochloramine residuals were maintained stable in the low-nutrient water pipes, which contributed to the inhibition of biofilm density. Increasing the monochloramine residual from 0.5 to $2.0 \mathrm{mg} / \ell$ suppressed the total cells and heterotrophic plate count (HPC) bacteria in the biofilms by about 1 and $2 \log$ units, respectively. The biofilm HPC densities were more sensitive to monochloramine residual, and the reduction in biofilm HPC densities expressed as $\log \mathrm{CFU} / \mathrm{cm}^{2}$ showed an exponential relationship with the increase in monochloramine residual. The Biolog micro-plate-based community-level assay showed that the biofilm communities occurring at 3 levels of chloramination were distinguished by the differences in their substrate utilisation potentials. The functional/metabolic potential of the biofilm community's ability to utilise specific substrates was much lower at higher monochloramine concentration. Results suggest that the maintenance of a consistently high-level monochloramine residual in the low-nutrient water system led not only to a reduction in biofilm density on pipe surfaces but also depressed potential functional/metabolic ability of the biofilm community.
\end{abstract}

Keywords: biofilm, monochloramine residual, low-nutrient water, HPC, physiological substrate utilisation profile, GAC

\section{Introduction}

Biofilms are aggregates of surface-associated micro-organisms in water distribution systems and can cause water qualityrelated problems, including bacterial regrowth, increased disinfectant demand (Lu et al., 1999), and taste and odour problems to the water (Nagy and Olson, 1985; Astier et al., 1995). Public concern for safe drinking water has brought the issue of biofilm density and subsequent growth to the forefront in water supply research.

The addition of chlorine or monochloramine is one of the most common methods of controlling biofilm density in water distribution systems. Despite some evidence showing the inefficiency of chlorination in inactivating biofilm bacteria, free chlorine is widely used in many countries. However, some studies have shown that monochloramine is superior to free chlorine in its potential for biofilm control (LeChevallier et al., 1988; Momba et al., 1999). Increasing chloramination practice in water utilities would be due to the prolonged persistence of monochloramine in the system. The use of monochloramine helps to reduce the formation of disinfection by-products. Under certain conditions, monochloramine was reported to penetrate better into biofilms

\footnotetext{
* To whom all correspondence should be addressed.

용 +65 6516 1216; fax: +65 65165266 ;

e-mail: parkphd@empal.com

Received 29 October 2007; accepted in revised form 22 April 2008
}

than free chlorine, because it seems to have a lower capacity for reaction with biofilm constituents (Griebe et al., 1994; Stewart et al., 2001). Although it is a weaker biocide than chlorine, it was shown to be effective when tested against biofilms. The efficacy of chlorine and monochloramine was compared using Pseudomonas aeruginosa biofilms grown in an annular biofilm reactor (Griebe et al., 1994); a dose of $4 \mathrm{mg} / \ell$ of monochloramine was found to be more effective for biofilm inactivation than a dose of $10.8 \mathrm{mg} / \ell$ of free chlorine. A disadvantage of monochloramine, however, is that longer contact times or higher concentrations are required to obtain similar results to those achieved with chlorine (Chandy and Angles, 2001).

Chloramines are produced by substitution reactions between free chlorine and ammonia in a process called chloramination. The forms of chloramine are monochloramine $\left(\mathrm{NH}_{2} \mathrm{Cl}\right)$, dichloramine $\left(\mathrm{NHCl}_{2}\right)$, and trichloramine $\left(\mathrm{NCl}_{3}\right)$; monochloramine is the predominant species under conditions typically found in drinking water treatment (Wolfe et al., 1984). Traditionally, chloramination is practised at a 3:1 dosing ratio of chlorine to ammonia by weight to optimise monochloramine formation (Hass, 1999).

Although chloramine is considered a more stable disinfectant than chlorine, it can disappear from the water distribution system through reactions involving both corroded pipe surfaces and natural organic matter in bulk water (Vikesland et al., 1998; Vikesland and Valentine, 2000). It is therefore emphasised that a consistent chloramine residual in the distribution system to control biofilm levels should be maintained. Chandy and Angles 
(2001) proposed that the treatment and system management strategies should incorporate nutrient removal to limit biofilm development through a combination of retarding bacterial growth and enhancing disinfectant persistence. It is generally recognised that a reduced level of nutrients, such as biodegradable organic matter (BOM) available for microbial growth, decreases disinfectant demand and increases its stability, allowing the optimisation of its dosage and minimising its disappearance during distribution. Thus, a greater reduction in biofilm levels would be expected with simultaneous lowering of nutrient levels and maintaining higher disinfectant residuals within the system.

It is very difficult to fully remove the untreated water organic matrix in a conventional water treatment process (Volk and LeChevallier, 2002). Indeed, drinking waters were found to contain residual organic matter and its biodegradable fraction. A granular activated carbon (GAC) filter is often chosen as the approach for controlling BOM levels in drinking water. Previous studies showed that GAC can be highly effective for BOM removal (Volk and LeChevallier, 1999; Norton and LeChevallier, 2000). The removal of BOM by GAC is attributed to adsorption, as well as biodegradation by the activity of microbial communities that colonise the external surface and the macro-pores of GAC particles (Urfer et al., 1997; Fonseca et al., 2001). Therefore, this filter can be used in the treatment of drinking water to limit the amount of utilisable nutrients that pass into the distribution system.

The objectives of this study were to investigate the efficacy of monochloramine residuals for controlling biofilm levels (total cells and culturable heterotrophic bacteria) in nutrientlimited water produced by GAC filtration, and to characterise the functional potential of the biofilm communities that develop at different levels of residual monochloramine. For this purpose, GAC-treated water samples were chloraminated as part of the treatment process. Three test runs were carried out under different monochloramine residual concentrations $(0.5,1.0$ and $2.0 \mathrm{mg} / \ell)$

\section{Materials and methods}

\section{Experimental system and conditions}

The experiments were performed using a laboratory-scale simulated distribution system (Fig. 1). The system consisted of two sets of identical drinking water distribution pipes. The distribution pipe was $5 \mathrm{~m}$ long, with an internal diameter of $3 \mathrm{~cm}$. In total, 80 removable test plugs were installed and sacrificed as biofilm sampling devices in each distribution pipe (Fig. 1). For biofilm density, a polyvinyl chloride (PVC) coupon, with a surface area of $2.0 \mathrm{~cm}^{2}$, was mounted on each plug.

Tap water was used throughout the experiment; this water had been produced at a nearby water treatment plant that used coagulation, sedimentation, sand filtration, and chlorination.. The chemical and biological characteristics of the tap-water are listed in Table 1. In order to remove nutrients, including organic carbon, from the tap-water, a GAC column was installed upstream of the simulated drinking water distribution system. This column was made of acrylic resin pipe, with a diameter of $35 \mathrm{~cm}$ and height of $160 \mathrm{~cm}$, and was filled with $40 \mathrm{~kg}$ of GAC (SLS 100, Samchully Activated Carbon Co., Korea) with $8 \times 30$ mesh. A $51 \mu \mathrm{m}$ nominal pore size stainless steel filter (Spectra $\mathrm{Mesh}^{\circledR}$, Spectrum Laboratories, Inc.) was placed at the top of the GAC to prevent the release of carbon particles during column operation. The column was operated in upflow mode, with an empty bed contact time of $25 \mathrm{~min}$.

In the nutrient-limited water, desired monochloramine residuals were $0.5,1.0$, and $2.0 \mathrm{mg} / \ell$, respectively. They were produced in situ by adding chlorine and ammonia to rapidly mixed water in a contactor (Fig. 1). A chlorine-to-ammonia dosing ratio of 3:1 (on a weight basis) was selected to achieve target residuals, which may no longer be reflective of current practices. Chlorine and ammonia stock solutions were prepared by diluting 6\% (as active chlorine) sodium hypochlorite $(\mathrm{NaOCl}$, Yakuri Pure Chemicals Co., Ltd., Japan) and $2 \mathrm{M}$ ammonium chloride $\left(\mathrm{NH}_{4} \mathrm{Cl}\right.$, Junsei Chemical Co. Ltd., Japan) solutions, respectively. Both solutions were independently pumped into Contactor 1 at a rate of $6.0 \mathrm{m \ell} / \mathrm{min}$ using two peristaltic pumps 
and were mixed for $10 \mathrm{~min}$ to allow production of desired monochloramine concentration at ambient $\mathrm{pH}(7.2 \pm 0.2)$ and temperature $\left(13.5 \pm 1.0^{\circ} \mathrm{C}\right)$, prior to passing into Contactor 2 . The primary purpose of Contactor 2 was to provide disinfection, which was accomplished by controlling contact time to meet the identical disinfection requirement (concentration times time, $\mathrm{C} \times \mathrm{T}$ ). It was necessary to minimise the influence of bacterial levels on the microbiology of the model distribution pipe. The nominal contact time applied was 40,20, $10 \mathrm{~min}$ for $0.5,1.0$, and 2.0 $\mathrm{mg} / \ell$ monochloramine concentrations, respectively. These times were based on $20 \mathrm{mg} / \ell \cdot \mathrm{min}$ of CT value. During the course of the study, the average monochloramine residual concentrations measured at Contactor 2 before entering the model distribution pipe were $0.48 \pm 0.05 \mathrm{mg} / \ell(n=42), 0.99 \pm 0.05 \mathrm{mg} / \ell(n=42)$, and $2.04 \pm 0.07 \mathrm{mg} / \ell(n=36)$, respectively. In addition, the total chlorine-to-ammonia ratio ranged between 3.1:1 and 3.3:1 in all experiments. Monochloramine and chlorine were measured using the $N, N$-diethyl-p-phenylenediamine ferrous titrimetric method (4500-Cl F), and ammonia was determined using the phenate method (4500-NH $\mathrm{NH}_{3}$ F) (Standard Methods, 1998).

The chloraminated water was pumped from the contact tank at a flow rate of $1.0 \mathrm{\ell} / \mathrm{min}$ into the simulated drinking water distribution pipe using a peristaltic pump. The theoretical hydraulic retention time in the pipe was calculated as $4 \mathrm{~min}$. The Reynolds number was approximately 500, indicating laminar flow in the simulated distribution pipes. A water temperature of 13 to $15^{\circ} \mathrm{C}$ was maintained during the experiments, and each run continued for 3 months.

\section{Biofilm sampling}

Biofilm samples that had formed on the surface of the PVC coupons were collected by randomly sacrificing test plugs. The coupon was removed from the test plug and transferred to a $100 \mathrm{~m} \ell$ Pyrex bottle that contained $60 \mathrm{~m} \ell$ of sterile $0.3 \mathrm{mM}$ phosphate buffer solution ( $\mathrm{pH}$ 7.2). The bottle was then submerged in an ultrasonic cleaner (Model 2210, Bransonic ${ }^{\circledR}$, Danbury, CT, USA) and sonicated three times for $9 \mathrm{~min}$. The biofilm was scraped manually from the tag into phosphate buffer using a sterile cell scraper (Becton Dickinson \& Co., Franklin Lakes, NJ, USA).

\section{Total and culturable counts of biofilm bacteria}

The enumeration of total cells for biofilm samples was performed by 4', 6-diamidino-2-phenylindole (DAPI) staining method (Saby et al., 1997). The sample of biofilm suspension was filtered through an $0.22 \mu \mathrm{m}$ black polycarbonate membrane (Millipore Korea Co., Ltd.). The filter was covered with $0.5 \mathrm{m \ell}$ of $1.0 \mu \mathrm{g} / \mathrm{m} \ell$ DAPI (Merck, Darmstadt, Germany) and $1.0 \mathrm{~m} \ell$ of $0.1 \%(w / v)$ Triton X-100 (USB Corp., Cleveland, OH, USA) solutions in the filter funnel apparatus. After $10 \mathrm{~min}$ of incubation in the dark, the filter was rinsed with sterile water, air-dried, and then mounted with non-fluorescent immersion oil on glass microscope slides. The filters were examined using an epifluorescence microscope (Model BX51, Olympus, Melville, NY, USA) with $1000 \times$ magnification. At least 20 fields were counted and the results were expressed as cells $/ \mathrm{cm}^{2}$.

Heterotrophic plate count (HPC) in each biofilm sample was analysed by the Standard Methods (1998) spread-plate method $(9215 \mathrm{C})$ or the membrane filter method $(9215 \mathrm{D})$ or both using R2A agar (Difco Laboratories, Detroit, MI, USA). The membrane filter technique was applied for a biofilm sample which was suspected of having an unacceptable count $(<30$ colony forming units (CFU)) on the spread plate. R2A-agar plates and filters were incubated at $25^{\circ} \mathrm{C}$ for $7 \mathrm{~d}$ before counting the colonies. Analysis of HPC was performed in duplicate and the results were expressed as $\mathrm{CFU} / \mathrm{cm}^{2}$.

\section{Community-level assay}

The community-level assay using Biolog gram-negative (GN) micro-plates (Biolog Inc., Hayward, CA, USA) produces community-level physiological profiles (CLPP) based on patterns of oxidation of the different carbon sources that were available to the growing organisms. A Biolog GN micro-plate consists of 96 wells, 95 of which contain different pre-dried carbon sources, whereas the remaining well is a carbon-free control. Each well also contains a tetrazolium violet redox dye that turns purple when the inoculated micro-organisms use the carbon source (Garland and Mills, 1991).

The community-level assay was accomplished as follows. Aliquots $(150 \mu \ell)$ of the biofilm suspensions that were recovered from the coupons were inoculated directly into each well of the micro-plates, which were then incubated at $30^{\circ} \mathrm{C}$ for $5 \mathrm{~d}$ (Park et al., 2006). The extended incubation period (5 d) was employed to remove the considerable effect of inoculum density (Wünsche et al., 1995). Colour development in the wells was monitored by measuring absorbance at $590 \mathrm{~nm}$ using a micro-plate reader (Molecular Devices Spectra Max 250, GMI Inc., Ramsey, MN, USA). The absorbance of each well was compared to that of the carbon-free control well. Negative absorbance was considered zero in subsequent data analyses. To eliminate weak false-positive responses, wells with an absorbance $>0.25$ units after correction using the control well were considered positive (Garland, 1996). Duplicate tests were conducted for each sample.

The CLPP patterns were analysed by computing the number of used substrates and the metabolic potential index (MPI). In the micro-plate system, the number of used substrates was defined as the total number of positive wells (Zak et al., 1994). The MPI was calculated by multiplying the number of positive wells by the average absorbance of the wells on the Biolog GN micro-plate as follows (Park et al., 2006):

$$
M P I=S \sum_{i=1}^{95} A_{i} \cdot p_{i}
$$

where:

$S$ is the total number of positive wells

$A_{i}$ is the absorbance of the $i$ th positive well

$p_{i}$ is the ratio of the absorbance of the $i$ th positive well to the total absorbance of all positive wells

$i$ is the well number $(1,2,3, \cdots, 95)$; thus,

$A \cdot p$ is the average absorbance exhibited in the micro-plate

MPI was developed to express the metabolic potential or functional potential of the microbial community as an absolute value.

\section{Water analysis}

HPC levels present in the water phase were determined by the spread-plate method or the membrane filter method or both using R2A agar (Standard Methods, 1998). The membrane filter method was used for a sample which was suspected of being difficult to enumerate $(<10$ to $300 \mathrm{CFU} / \mathrm{m} \ell)$ by the spread-plate method due to low counts. Plates and filters were then incubated for $7 \mathrm{~d}$ at $25^{\circ} \mathrm{C}$ before counting the colonies. The results were expressed as $\mathrm{CFU} / \mathrm{m} \ell$.

Total organic carbon (TOC) was measured using a TOC 
analyser (Model Phoenix 8000, Tekmar-Dohrmann, Cincinnati, OH, USA). Assimilable organic carbon (AOC) concentrations were measured using Pseudomonas fluorescens strain P17 and Spirillum sp. strain NOX method (9217) of Standard Methods (1998). Biodegradable dissolved organic carbon (BDOC) levels were determined using an assay that uses bacteria attached to sand (Park et al., 2004). The $\mathrm{pH}$ was measured using an Orion model 710A pH meter (Thermo Orion, Beverly, MA). Alkalinity, hardness, and phosphate were analysed with the titration method using mixed bromocresol green-methyl red indicator (2320 B), the ethylenediaminetetraacetic acid titrimetric method (2340 C), and ascorbic acid method (4500-P E) of Standard Methods (1998), respectively.

\section{Statistical analysis}

The experimental data were analysed using the statistical program Minitab (Release 13, Minitab Inc., PA, USA). Statistical differences were tested with t-test and one-way analysis of variance (ANOVA). Acceptance or rejection of the null hypothesis was based on a significance level of 0.05 in all cases.

\section{Results and discussion}

\section{Nutrient and HPC levels entering the system}

The GAC-treated water quality during the experiment is presented in Table 1. During the course of the study, most of the GAC-treated water characteristics remained stable, except for the HPC. The average TOC concentration was reduced from 0.65 to $0.18 \mathrm{mg} / \ell$ following the GAC column treatment, which represents a significant (as high as $80 \%$ ) reduction in $\mathrm{BOM}$. The average AOC and BDOC concentrations in the GAC column effluent were $10.5 \mu \mathrm{g} / \ell$ and $0.055 \mathrm{mg} / \ell$, respectively (Table 1 ). Unlike organic carbon, however, ammonia and phosphate were not significantly removed by the GAC column throughout the experiment. No measurable amount of free or combined chlorine was detected in samples of GAC effluent (Table 1). After the GAC treatment, organic carbon and its biodegradable fraction were very low, but high bacterial counts were observed at the outlet of the filter. The number of culturable heterotrophic bacteria in the GAC column effluents averaged $2.1 \times 10^{3} \mathrm{CFU} / \mathrm{m} \ell$ and ranged between $9.0 \times 10^{1}$ and $6.3 \times 10^{3} \mathrm{CFU} / \mathrm{m} \ell$ during the experiment (Table 1). This could be due to bacterial cells emanating from the filter.

Water samples that passed through the GAC filter were subsequently chloraminated with different residual concentrations as part of the treatment process. Bacterial counts were performed in the chloraminated water entering the model distribution pipes. The values of HPC after chloramination of GACtreated water are shown in Fig. 2. HPC levels present in GACtreated water were inactivated more than $99 \%$ by dosing $0.5,1.0$, and $2.0 \mathrm{mg} / \ell$ of monochloramine. On average, HPC levels measured at the influent water of the model distribution pipe were 5.1 $\mathrm{CFU} / \mathrm{m} \ell$ (range, $1.0 \times 10^{0}$ to $1.8 \times 10^{1} \mathrm{CFU} / \mathrm{m} \ell$ ), $3.8 \mathrm{CFU} / \mathrm{m} \ell$ (range, $5.2 \times 10^{-2}$ to $1.1 \times 10^{1} \mathrm{CFU} / \mathrm{m} \ell$ ), and $3.3 \mathrm{CFU} / \mathrm{m} \ell$ (range, $2.0 \times 10^{-2}$ to $1.2 \times 10^{1} \mathrm{CFU} / \mathrm{m} \ell$ ) for $0.5,1.0$, and $2.0 \mathrm{mg} / \ell$ of monochloramine residual concentrations, respectively (Fig. 2). One-way ANOVA showed that differences in HPC levels of influent water among the monochloramine concentrations applied were not statistically significant $(\mathrm{F}=2.62, \mathrm{P}=0.078)$. It is therefore expected that the influent bulk bacterial levels would have little significance on the microbiology of the model distribution pipes with different monochloramine residual concentrations.

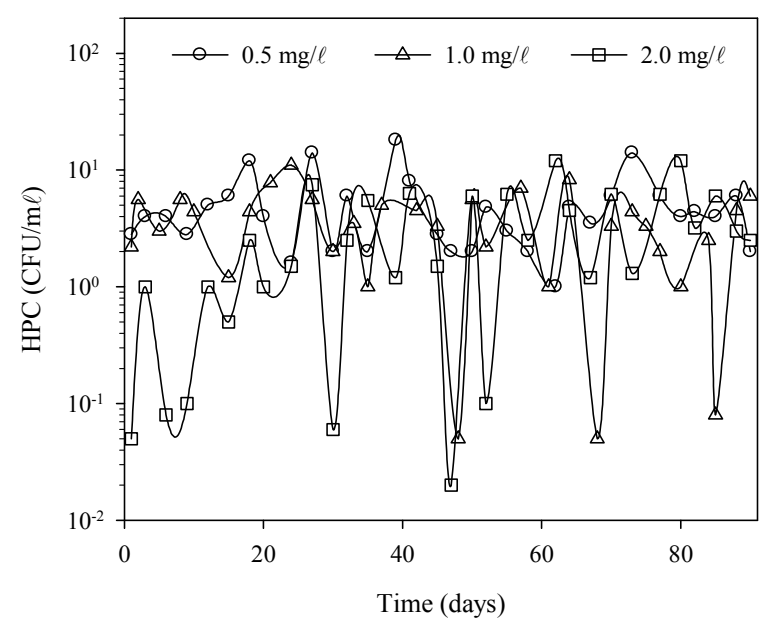

Figure 2

HPC levels for influent water entering the model distribution pipe

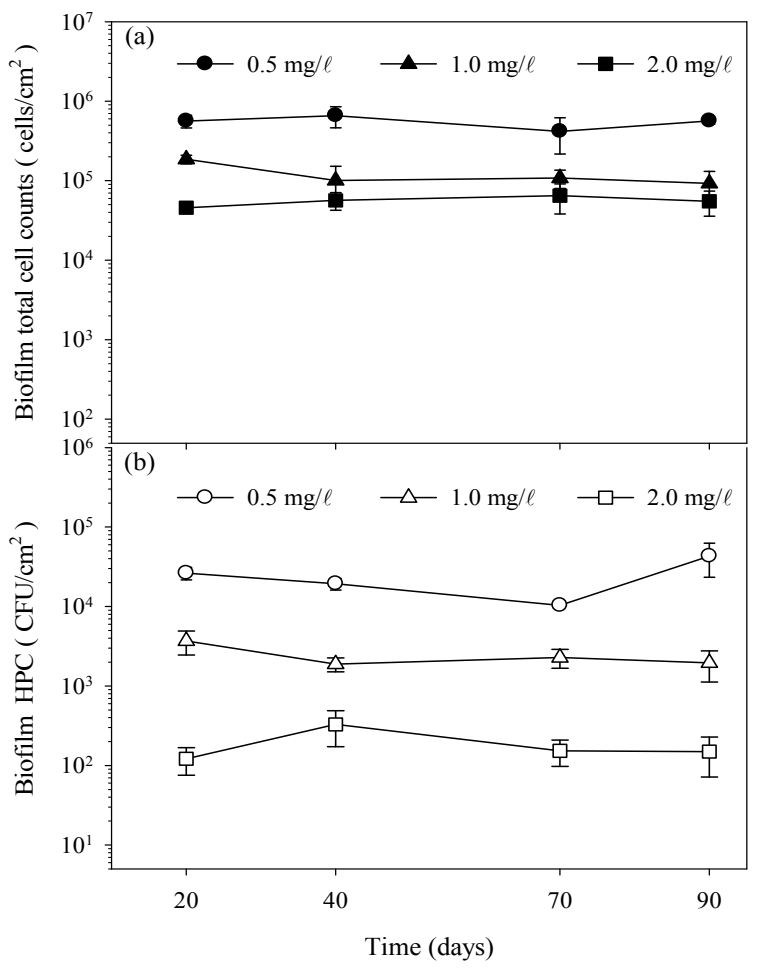

Figure 3

(a) Total cells and (b) HPC levels in the biofilms that developed in the model distribution pipes fed with GAC-treated monochloraminated water

\section{Biofilm bacteria densities}

For all three test runs, the monochloramine residuals within the model distribution pipe remained stable over the course of the experiment. Indeed, measurements of monochloramine residual carried out periodically at the outlet of the model distribution pipe gave virtually the same results as at the inlet (data not shown), indicating that a loss of monochloramine residual within the pipe was virtually zero. In this case, low-nutrient water is preferable in maintaining a stable target monochloramine residual. This is supported by literature findings (Chandy and Angles, 2001; Wilczak et al., 2003).

Figure 3 shows the total and culturable cell counts in the biofilms that developed in the model distribution pipes fed 
with GAC-treated monochloraminated water. The considerable bacterial colonisation was rapidly observed within a few days despite the influx of monochloraminated water. Changes in the bacterial levels in the biofilms after Day 20 were not substantial for all pipes, which may explain a quasi-steady state of biofilm. Total cell counts in the biofilm tended to decrease when the monochloramine residual increased from 0.5 to $2.0 \mathrm{mg} / \ell$ (Fig. 3a), which indicates that there was an overall decrease in the biofilm density. Throughout the 3 months of operation, the overall mean number of total cells in the biofilm was $5.5 \times 10^{5} \pm 9.9 \times 10^{4}, 1.2 \times 10^{5} \pm 4.3 \times 10^{4}$, and $5.6 \times 10^{4} \pm 7.8 \times 10^{3} \mathrm{cells} / \mathrm{cm}^{2}$ at $0.5,1.0$, and $2.0 \mathrm{mg} / \ell$ of monochloramine residual concentration, respectively (Fig. 3a). A $t$-test revealed that there was a significant difference between the biofilm total cells at 0.5 and $1.0 \mathrm{mg} / \ell$ of monochloramine residual $(\mathrm{P}=0.005)$, but there was no significant difference between those at 1.0 and $2.0 \mathrm{mg} / \ell$ of monochloramine residual $(\mathrm{P}=0.077)$.

The mean of the biofilm HPC densities was $2.5 \times 10^{4} \pm 1.4 \times 10^{4}$, $2.5 \times 10^{3} \pm 8.5 \times 10^{2}$, and $1.9 \times 10^{2} \pm 9.5 \times 10^{1} \mathrm{CFU} / \mathrm{cm}^{2}$ at $0.5,1.0$, and $2.0 \mathrm{mg} / \ell$ of monochloramine residual, respectively (Fig. $3 \mathrm{~b}$ ). The culturable, adherent HPC levels in the presence of $0.5,1.0$, and $2.0 \mathrm{mg} / \ell$ of monochloramine residual corresponded to $4.4 \pm 2.3 \%$, $2.0 \pm 0.1 \%$, and $0.3 \pm 0.2 \%$ of the total biofilm cells, respectively. One-way ANOVA revealed that differences between HPC levels in the biofilm were statistically significant $(\mathrm{F}=11.05, \mathrm{P}=0.004)$. This implies that the biofilm HPC could be much more sensitive to the monochloramine residual maintenance when going from low to high level. The biofilm HPC densities decreased by $1.00 \pm 0.29$ and $2.12 \pm 0.35 \log \mathrm{CFU} / \mathrm{cm}^{2}$ in the presence of 1.0 and $2.0 \mathrm{mg} / \ell$ of monochloramine residual, respectively, compared to those at the monochloramine concentration of $0.5 \mathrm{mg} / \ell$. Results show that the ratio of HPC to total cell counts in biofilms decreases with increasing the monochloramine residual, indicating that bacterial cells lose their ability to grow on culture media.

The data in Fig. 4 suggest that the biofilm HPC levels are not controlled by the influent HPC levels. It might result from the control of influent bulk bacteria provided through appropriate $\mathrm{CT}$ credit before entering the model distribution pipe. Therefore, it can be sure that the biofilm behaviour is mainly affected by the monochloramine residual concentration under nutrient limitation, although the bacteria present in influent water may still attach to the surface and participate to the biofilm accumulation. Past studies reported that the bulk bacteria passing through the water treatment plant contribute to biofilm accumulation (LeChevallier et al., 1987; Van der Wende et al., 1989). However, their contribution seems to have a minor effect compared to the internal growth of the attached cells depending on the experimental conditions (nutrients, biocides, etc.).

Under the lack of nutrient flux, the biofilm HPC density depending on the concentration of monochloramine residual was expressed as an exponential equation of the following form using the dataset:

$$
B_{f}=\Phi \exp (-k \cdot C)
$$

where:

$$
\begin{aligned}
& B_{f} \text { is the biofilm HPC density expressed in } \log \mathrm{CFU} / \mathrm{cm}^{2} \\
& C \text { is the monochloramine concentration }(\mathrm{mg} / \ell) \\
& k \text { and } \Phi \text { are experimental constants }
\end{aligned}
$$

This exponential regression fit well, with a coefficient of determination $\left(R^{2}\right)$ of 0.997 , demonstrating a very strong dependence of biofilm HPC densities on monochloramine residuals (Fig. 5).

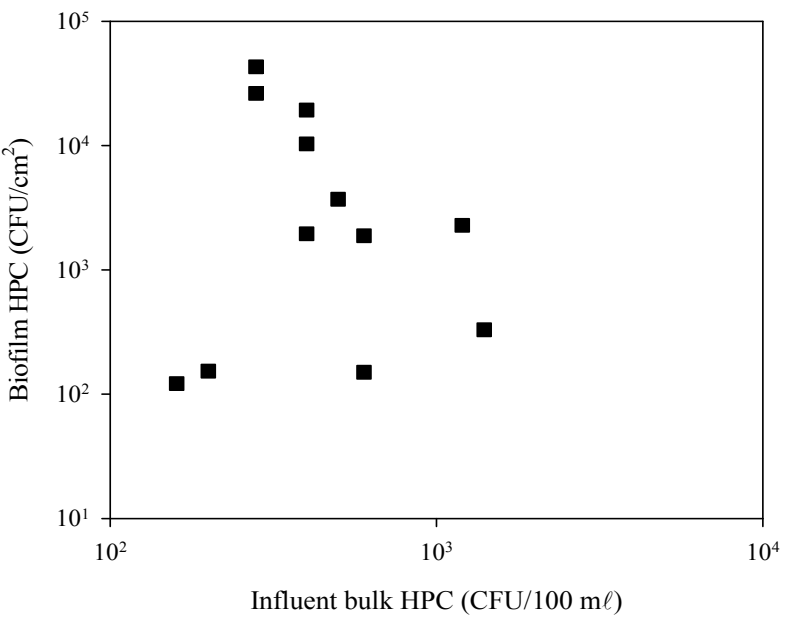

Figure 4

Biofilm HPC levels versus influent bulk HPC levels in the model distribution system

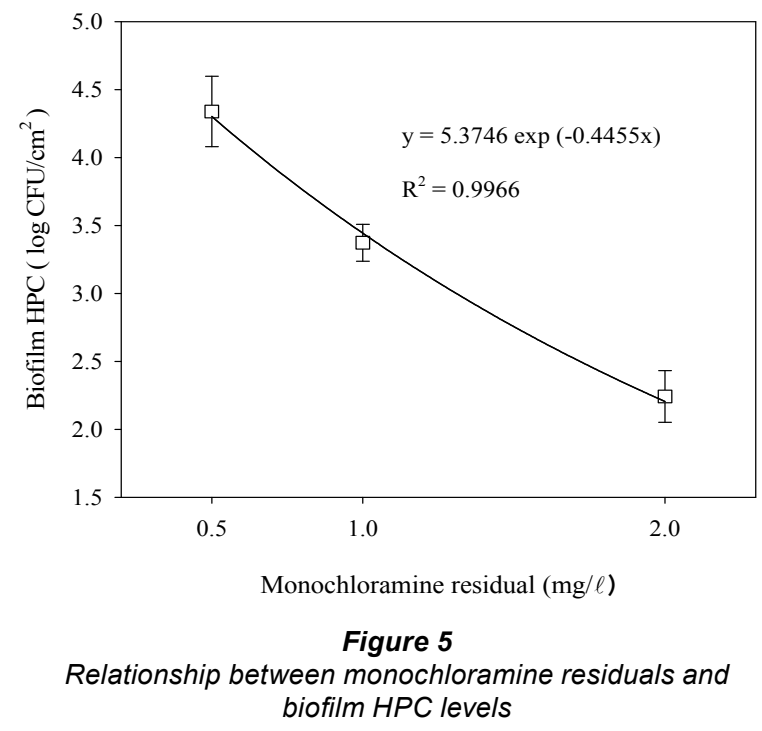

The regression equation gave 0.4455 and 5.3746 for $k$ and $\Phi$, respectively, suggesting that under the experimental conditions of nutrient limitation, 13 to $15^{\circ} \mathrm{C}$, and laminar flow, more than $3 \mathrm{mg} / \ell$ of monochloramine residual is required to reduce the biofilm HPC levels to $<10^{1} \mathrm{CFU} / \mathrm{cm}^{2}$.

The experimental results indicate that the maintenance of a consistent monochloramine residual in the low-nutrient water contributed to the suppression of biofilm levels on the pipe surfaces. The high residual system demonstrated consistently lower bacterial culturability in the biofilm than low residual counterparts did. It was expected that the nutrient limitation in water would reduce the level of monochloramine residual required for controlling biofilm levels when the study began, even if the nutrient limitation itself may not be sufficient to prevent these (Park et al., 2006). Unexpectedly, the data suggested that the maintenance of a higher monochloramine residual is required for limiting biofilm levels in spite of the provision of low-nutrient water using the GAC filter. It could therefore be argued that it is difficult to reduce the level of monochloramine residual by the nutrient limitation itself. The efficacy of disinfectant residual can be affected by three groups (Barbeau et al., 2005):

- Variables (e.g., pH, temperature, etc.) influencing the activity of the disinfectant 
- Variables (e.g., inorganic and organic nutrients, etc.) interfering with the availability of the disinfectant in water

- Variables (e.g., turbidity, etc.) interfering with the accessibility of the disinfectant to the target micro-organism.

Therefore, further studies, which take other variables into account, need to be undertaken to reduce the level of monochloramine residual required for limiting biofilm density.

Under the influx of nutrient-limited monochloraminated water, presence of undesirable biofilm bacteria may be related to the interplay of several resistance mechanisms (Donlan and Pipes, 1988; Rogers et al., 1994; Szewzyk et al., 1994; Fass et al., 1996), which may facilitate biofilm chronicity and thereby lead to an increase in monochloramine dose within the distribution system. Stewart and Olson (1992) suggested that physiological changes may be primed for survival against chloramination under a low-nutrient environment. The physiological state of cells and the nature of the habitat may lead to considerable variation in the susceptibility of bacteria to disinfectant.

Compared to the results of a previous study (Park et al., 2006) that had used free chlorine under the same operating conditions, the biofilm HPC levels were 1 order of magnitude higher in the present study (monochloramine residual pipe) than those observed in the free chlorine residual pipe at the same residual concentration. This might result from the reduction of nutrients present in water. Biofilm bacteria seem to be more sensitive to free chlorine than monochloramine in water systems where the nutrients interfering with the availability of disinfectant residuals are limited. Although the specific residual required for control may be different in different systems, the monochloramine residual would need to be maintained above the free chlorine level at the specific condition. In actual distributions systems, generally, the feasibility of maintaining monochloramine as well as free chlorine residuals may be subject to the prevailing conditions of distribution system (water quality, pipe characteristics, etc.) or a number of constraints (disinfection by-product formation, etc.). Recently, Momba and Makala (2004) proposed a combination of chlorine and monochloramine for the effective removal and inhibition of bacterial biofilm in drinking water systems. Monochloramine as a disinfectant has distinct benefits, as mentioned earlier, and still plays a substantial role in minimising the possibility of biofilm development in an effort to improve the quality of potable water.

\section{Functional potential of biofilm communities}

In the present study, the physiological characteristics of the biofilm communities occurring at each of the three chloraminated systems were assessed on the basis of analysis of the physiological utilisation profiles using the Biolog GN micro-plate-based community-level assay. For this purpose, the original, undiluted suspension of biofilm micro-organisms was inoculated directly into Biolog micro-plate wells, and the results were read after a fixed incubation period. It allows a functional/metabolic profile of the bacterial community's ability to utilise specific carbon sources on Biolog micro-plates (Wünsche et al., 1995).

The biofilm communities that were recovered from each of the three chloraminated systems on Days 20, 40, 70, and 90 displayed distinctive substrate utilisation profiles. Although the carbon substrates on the Biolog GN micro-plates do not accurately represent the carbon substrates that are present in drinking water, either in type or concentration, the patterns generated from this community-level assay appear to be a function of the original microbial community This is because many micro-

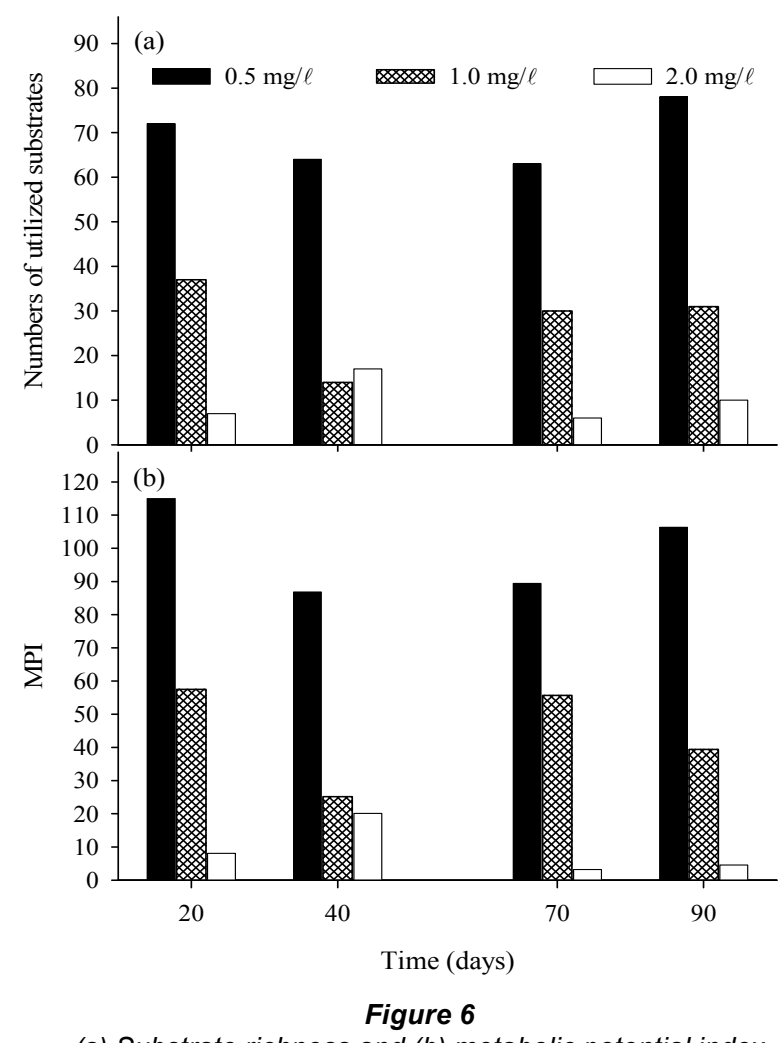

(a) Substrate richness and (b) metabolic potential index (MPl) of the biofilm communities originating from the three monochloramine residual $(0.5,1.0$, and $2.0 \mathrm{mg} / \mathrm{l})$ pipes

organisms have the genetic potential to use a specific substrate; that is, they display metabolic redundancy (Konopka et al., 1998).

Throughout the course of the experiment, biofilm communities originating from $0.5,1.0$, and $2.0 \mathrm{mg} / \ell$ monochloramine residual pipes utilised 85,67 , and $28 \%$ of the available Biolog carbon substrates, respectively. It was observed that the utilisation profiles of biofilm communities for the offered carbon substrates varied somewhat over the 3-month monitoring period, even on the same system. Some carbon substrates were always utilised, while others were not consistent from time to time. One reason for this time-dependent variation may be temporal changes in the species composition and physiological heterogeneity of the biofilm.

Substrate richness, the number of carbon substrates that were utilised by the biofilm communities recovered from the three chloraminated systems is summarised in Fig. 6a. The substrate richness values of the biofilm communities recovered from 0.5 $\mathrm{mg} / \ell, 1.0 \mathrm{mg} / \ell$, and $2.0 \mathrm{mg} / \ell$ monochloramine residual pipes were 63 to 78,14 to 37, and 6 to 17, respectively. In addition to substrate richness, as shown in Fig. 6b, MPI values of biofilm communities recovered from $0.5 \mathrm{mg} / \ell, 1.0 \mathrm{mg} / \ell$, and $2.0 \mathrm{mg} / \ell$ monochloramine residual pipes were 86.9 to $115.0,25.1$ to 57.5 , and 3.2 to 20.1, respectively. Biofilm communities with the lowest substrate richness as well as the lowest activity levels (summation of absorbance values) showed the lowest MPI, which is a reflection of the limited response to specific carbon substrates.

Differences in the observed physiological profiles among the biofilm communities recovered from the three chloraminated pipes remained constant. Since positive responses to carbon substrates may be affected by the presence of active cells in a community (Haack et al., 1995), a significantly decreased functional and/or metabolic potential of the biofilm communities that 
had been subjected to higher monochloramine residual would be attributable to a greater proportion of non-active cells. Focusing on the overall trends, the shifts in functional attributes of the biofilm communities were considered similar to the biofilm culturable HPC data, whereby both of them were sensitive to the monochloramine residual maintenance. Therefore, it can be said that the inhibitory effect of the consistent monochloramine residual maintenance on the establishment of biofilms was characterised not only by loss of bacterial culturability but also by reduced potential functional/metabolic ability of the biofilm communities.

\section{Conclusions}

This study shows that the biofilm density in distribution pipes was notably affected by maintaining a stable monochloramine residual in the nutrient-limited (GAC-treated) water pipe. The total and culturable cell densities in the biofilms decreased significantly with increasing monochloramine residual concentration. Changes in bacterial levels in the biofilms affected by the presence of monochloramine residual were significantly higher when expressed as HPC than when expressed as total cell counts. The biofilm HPC densities expressed as $\log \mathrm{CFU} / \mathrm{cm}^{2}$ decreased exponentially with the increase in monochloramine residual. The Biolog micro-plate-based community-level assay showed that the biofilm communities occurring at 3 levels of chloramination were distinguished by the differences in their substrate utilisation potentials. The functional/metabolic potential of the biofilm community's ability to utilise specific substrates was much lower at higher monochloramine concentrations.

The study demonstrated the effectiveness of specific monochloramine concentrations on the biofilms in the nutrientlimited water system. It suggests that monochloramine concentrations may be required to be maintained at levels as high as $2 \mathrm{mg} / \ell$, even in nutrient-limited water, for improving the control of unwanted biofilms in drinking water distribution systems.

\section{Acknowledgements}

This study was supported by the Korea Science and Engineering Foundation (Grant No. R01-2003-000-10494-0). Additional support was provided by the Korea Research Foundation Grant funded by the Korean Government (MOEHRD) (KRF-2006352-D00127).

\section{References}

ASTIER F, PAQUIN JL, MATHIEU L, MORLOT M and HARTEMANN P (1995) Study of the development of the musty taste in water according to its ageing process in pilot plant. Environ. Technol. 16 955-965.

BARBEAU B, DESJARDINS R, MYSORE C and PRÉVOST M (2005) Impacts of water quality on chlorine and chlorine dioxide efficacy in natural waters. Water Res. 39 (10) 2024-2033.

CHANDY JP and ANGLES ML (2001) Determination of nutrients limiting biofilm formation and the subsequent impact on disinfectant decay. Water Res. 35 (11) 2677-2682.

DONLAN RM and PIPES WO (1988) Selected drinking water characteristics and attached microbial population density. J. Am. Water Works Assoc. 80 (11) 70-76.

FASS S, DINCHER ML, REASONER DJ, GATEL D and BLOCK JC (1996) Fate of Escherichia coli experimentally injected in a drinking water distribution pilot system. Water Res. 30 (9) 2215-2221.

FONSECA AC, SUMMERS RS and HERNANDEZ MT (2001) Comparative measurements of microbial activity in drinking water biofilters. Water Res. 35 (16) 3817-3824.
GARLAND JL and MILLS AL (1991) Classification and characterization of heterotrophic microbial communities on the basis of patterns of community-level sole-carbon-source utilization. Appl. Environ. Microbiol. 57 (8) 2351-2359.

GRIEBE T, CHEN CI, SRINIVASAN R and STEWART PS (1994) Analysis of biofilm disinfection by monochloramine and free chlorine. In: GG Geesey, Z Lewandowski and HC Flemming (eds.) Biofouling and Biocorrosion in Industrial Water Systems (152-161). Lewis, Boca Raton.

HAACK SK, GARCHOW H, KLUG MJ and FORNEY LJ (1995) Analysis of factors affecting the accuracy, reproducibility, and interpretation of microbial community carbon source utilization patterns. Appl. Environ. Microbiol. 61 (4) 1458-1468.

HASS CN (1999) Disinfection. In: RD Letterman (ed.) Water Quality and Treatment - A Handbook of Community Water Supplies (877-932). American Water Works Association, McGraw-Hill, New York.

KONOPKA A, OLIVER L and TURCO JR RF (1998) The use of carbon substrate utilization patterns in environmental and ecological microbiology. Microb. Ecol. 35 103-115.

LECHEVALLIER MW, BABCOCK TM and LEE RG (1987) Examination and characterization of distribution system biofilms. Appl. Environ. Microbiol. 53 (12) 2714-2724.

LECHEVALLIER MW, CAWTHON CD and LEE RG (1988) Inactivation of biofilm bacteria. Appl. Environ. Microbiol. 54 (10) 2492-2499.

LU W, KIÉNÉ L and LÉVI Y (1999) Chlorine demand of biofilms in water distribution systems. Water Res. 33 (3) 827-835.

MOMBA MNB and MAKALA N (2004) Comparing the effect of various pipe materials on biofilm formation in chlorinated and combined chlorine-chloraminated water systems. Water SA 30 (2) 175-182.

MOMBA MNB, CLOETE TE, VENTER SN and KFIR R (1999) Examination of the behavior of Escherichia coli in biofilms established in laboratory-scale using receiving chlorinated and chloraminated water. Water Res. 33 (13) 2937-2940.

NAGY LA and OLSON BH (1985) Occurrence and significance of bacteria, fungi, and yeasts associated with distribution pipe surfaces. Water Suppl. 11 (3-4) 365-376.

NORTON CD and LECHEVALLIER MW (2000) A pilot study of bacteriological population changes through potable water treatment and distribution. Appl. Environ. Microbiol. 66 (1) 268-276.

PARK SK, LEE SH, CHOI SC and KIM YK (2006) Characteristics of biofilm community formed in the chlorinated biodegradable organic matter-limited tap water. Environ. Technol. 27 (4) 377-386.

PARK SK, PAK KR, CHOI SC and KIM YK (2004) Evaluation of bioassays for analyzing biodegradable dissolved organic carbon in drinking water. J. Environ. Sci. Health A 39 (1) 103-112.

ROGERS J, DOWSETT AB, DENNIS PJ, LEE JV and KEEVIL CW (1994) Influence of plumbing materials on biofilm formation and growth of Legionella pneumophila in potable water systems. Appl. Environ. Microbiol. 60 (6) 1842-1851.

SABY S, SIBILLE I, MATHIEU L, PAQUIN JL and BLOCK JC (1997) Influence of water chlorination on the counting of bacteria with DAPI. Appl. Environ. Microbiol. 63 (4) 1564-1569.

STANDARD METHODS (1998) Standard Methods for the Examination of Water and Wastewater (20 ${ }^{\text {th }}$ edn.). American Public Health Association, American Water Works Association and Water Environment Federation, Washington DC.

STEWART MH and OLSON BH (1992) Physiological studies of chloramines resistance developed by Klebsiella pneumoniae under low-nutrient growth conditions. Appl. Environ. Microbiol. 58 (9) 2918-2927.

STEWART PS, RAYNER J, ROE F and REES WM (2001) Biofilm penetration and disinfection efficacy of alkaline hypochlorite and chlorosulfamates. J. Appl. Microbiol. 91 (3) 525-532.

SZEWZYK U, MANZ W, AMANN R, SCHLEIFER KH and STENSTROM TA (1994) Growth and in situ detection of a pathogenic Escherichia coli in biofilms of a heterotrophic water-bacterium by use of 16S- and 23S-rRNA-directed fluorescent oligonucleaotide probes. FEMS Microb. Ecol. 13 169-176.

URFER D, HUCK PM, BOOTH SDJ and COFFEY BM (1997) Biological filtration for BOM and particle removal: A critical review. 
J. Am. Water Works Assoc. 89 (12) 83-98.

VAN DER WENDE E, CHARACKLIS WG and SMITH DB (1989) Biofilms and bacterial drinking water quality. Water Res. 23 (10) 1313-1322.

VIKESLAND PJ and VALENTINE RL (2000) Reaction pathways involved in the reduction of monochloramine by ferrous iron. Environ. Sci. Technol. 34 (1) 83-90.

VIKESLAND PJ, OZEKIN K and VALENTINE RL (1998) Effect of natural organic matter on monochloramine decomposition: pathway elucidation through the use of mass and redox balances. Environ. Sci. Technol. 32 (10) 1409-1416.

VOLK CJ and LECHEVALLIER MW (1999) Impacts of the reduction of nutrient levels on bacterial water quality in distribution systems. Appl. Environ. Microbiol. 65 (11) 4957-4966.
VOLK CJ and LECHEVALLIER MW (2002) Effects of conventional treatment on AOC and BDOC levels. J. Am. Water Works Assoc. 94 (6) $112-123$

WOLFE RL, WARD NR and OLSON BH (1984) Inorganic chloramines as drinking water disinfections: a review. J. Am. Water Works Assoc. 76 (5) 74-88.

WÜNSCHE L, BRÜGGEMANN L and BABEL W (1995) Determination of substrate utilization patterns of soil microbial communities: an approach to assess population changes after hydrocarbon pollution. FEMS Microb. Ecol. 17 295-306.

ZAK JC, WILLIG MR, MOORHEAD DL and WILDMAN HG (1994) Functional diversity of microbial communities: A quantitative approach. Soil Biol. Biochem. 26 (9) 1101-1108. 